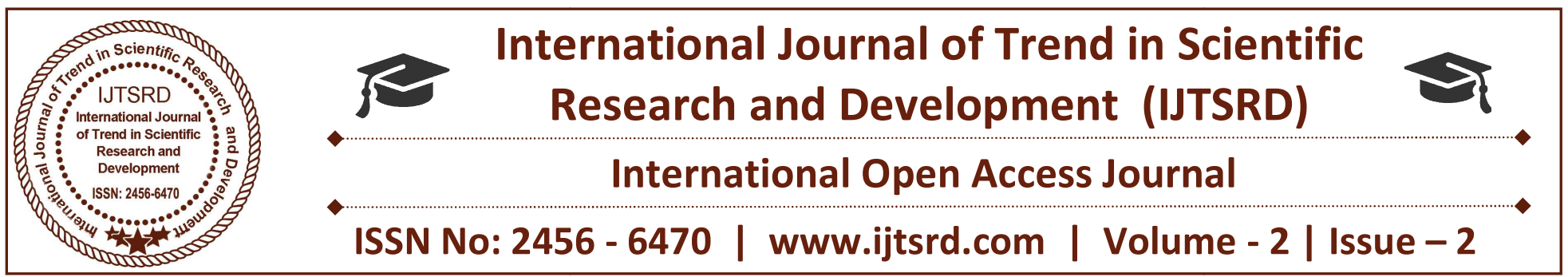

\title{
Influence of Goat Manure as Organic Amendment on Physical and Physico Chemical Properties of Therisoil
}

Indira, E.

Research Scholar, Manonmaniam

Sundaranar University,

Tirunelveli, Tamil Nadu
Annadurai, B.

Head, Department of Physics,

Aditanar College of Arts \&

Science,Tiruchendur, Tamil Nadu

\author{
Sundaram, S. \\ Associate Professor, Thiruvalluvar \\ College, Papanasam, Tamil Nadu
}

\section{ABSTRACT}

Theri lands are located along the coastal areas of Tuticorin district of Tamilnadu, South India. Proper management of the land is difficult because of its poor quality structure, low nutrition, meagre moisture holding capacity, low value of organic content, and high value of hydraulic conductivity. The permeability of water in theri soil is high and is not suitable for agriculture which is presently considered as a wasteland. The objective is to nurse the soil back to health and reclaim the soil. Goat Manure amended with theri soil characteristics are studied separately. In this amendment, ten different combinations are tried. Using this organic amendment the soil Physical, Physico-Chemical and Chemical properties are studied which makes the soil cultivable and to arrive at their interrelationships in reclaiming the soil. A field experiment is conducted at PunnaiNagar (Kachanavillai) that is located at $19 \mathrm{~km}$ west from Tiruchendur of Tuticorin district, Tamilnadu. This study tests for the changes of physical properties through the addition of goat manures and aims in describing relationship among the soil physical properties such as bulk density(BD),Particle density(PD), Water holding density(WHC), Pore space (PS),Hydraulic conductivity(HC), Thermal Conductivity(TC), Volume Expansion(VE) of the soil through various methods. Physico-Chemical properties like Electrical conductivity (EC), Potential of Hydrogen $(\mathrm{pH})$ and Chemical properties namely NPK, Organic Carbon (OC) are also studied.
Keywords: Theri soil, Goat Manure, Organic amendments, Water holding capacity, Hydraulic conductivity

\section{Introduction}

India is facing one of the largest challenges of this century to continue to increase annual food production to about $125 \mathrm{Mt}$ by 2020 to ensure food security with shrinking cropland and limited resources, while maintaining or improving soil fertility, and protecting the environment. Rich experiments in integrated and efficient utilization of different strategies of crop rotation, intercropping, and all possible nutrient resources accumulated by Indian farmers in traditional farming systems have been gradually abandoned and nutrient management shifted to over-reliance on synthetic fertilizers. On account of continuous world energy crisis with increasing prices of chemical fertilizer the use of organic manures as renewable sources of plant nutrients is gaining importance. In this endeavour proper blends of organic and inorganic fertilizer are of utmost important not only for increasing yield and for soil health and the continuous use of organic and inorganic soil amendments speed up the process of reclamation of soil. In addition nutrient availability from organic sources offer more balanced nutrition to the plants, especially micronutrients which has caused better tillering in plant growth, dry matter production and yield. The coastal red sandy dunal soils of Tamil Nadu are called Theri soils. They occur in the Tuticorin and Tirunelveli districts of Tamilnadu with 
an extend of 20,171 hectares (Jawahar 1996). The annual average rainfall of the area is between 610 to700mm (Jawahar et al., 1999 a). Now it is not suitable for agriculture and it is considered as a waste land because of its sandy texture and unfavorable topography. This study tests for the changes of physical properties through the addition of organic manures and aims in describing relationship among the soil physical properties such as bulk density(BD),Particle density(PD), Water holding density(WHC), Pore space (PS),Hydraulic conductivity(HC), Thermal Conductivity(TC), Volume Expansion(VE) of the soil through various methods. Physico-Chemical properties like Electrical conductivity (EC), Potential of Hydrogen $(\mathrm{pH})$ and Chemical properties namely NPK, Organic Carbon (OC) are also studied. The validity of the result is tested in Theri soil in Kachanavillai (Kurumbur), Tuticorin District, Tamilnadu, India. These observations are useful to the farmers of Tamilnadu for the sustainable productivity without making environmental pollution.

\section{Materials and Methods}

Soil samples (Theri soil ) were collected at Punnai nagar (Kachanavilai) that is located at $19 \mathrm{~km}$ west from Tiruchendur in Tuticorin district of Tamil Nadu. A soil sample was collected in the experimental site at a depth of $15 \mathrm{~cm}$ from the surface. It was dried and pass through $2 \mathrm{~mm}$ sieve for uniformity in size and analyzed for their physico-chemical and physical properties. A pot experiment was conducted during Rabi season during 2014- 2015. The experiment was laid out in a pot culture with ten treatments replicated thrice. The pots were arranged under the screen house according to steel and Torrie [6]. In the screen house study, 1 litre (1000 c.c) of theri soil thoroughly mixed with different percentage of Goat manure in a clay pot. (2 $\mathrm{mm}$ sieve powder). Ten different combinations, namely theri soil $(\mathrm{Th})+10 \%$ of Goat manure); $\mathrm{Th}+20 \%$ of Goat manure; $\mathrm{Th}+30 \%$ of Goat manure; $\mathrm{Th}+40 \%$ of Goat manure; $\mathrm{Th}+50 \%$ of Goat manure; $\mathrm{Th}+60 \%$ of Goat manure; $\mathrm{Th}+70 \%$ of Goat manure; $\mathrm{Th}+80 \%$ of Goat manure; $\mathrm{Th}+90 \%$ of Goat manure; $\mathrm{Th}+100 \%$ of Goat manure. These different combinations were thoroughly ameliorated mechanically before use. For example $\mathrm{Th}+10 \%$ of Goat manure mean $100 \mathrm{cc}$ of Goat manure was mixed with $1000 \mathrm{cc}$ of Theri soil. The volume of the soil is fixed. These mixtures were allowed to settle for a period of 90 days by wetting with water regularly and without allowing them to get dried. After 90 days measurements were made on the physical and physico-chemical properties, such as pH,EC, NPK, particle density, bulk density, porosity, water holding capacity, volume expansion, organic carbon content and hydraulic conductivity

\subsection{Methods Used for Analysis}

The soil samples were characterized for important physico-chemical properties using standard procedures. Bulk density, Particle density, Water holding capacity, Porosity,Volume expansion by KeenRaczkowski(KR) Box model [7], Soil pH and EC was determined in 1:2.5 soil water suspensions with help of glass electrode $\mathrm{pH}$ meter with a digital display and with a null balance conductivity meter correspondingly [8], Organic Carbon determined Chromic acid wet oxidation method [9]. Available "N" alkaline permanganate method [10]. The available "P" was estimated by Flame photometer [11] and available " $\mathrm{K}$ " determined by Ammonium acetate method [12]. Finally soil samples were collected from pots and air dried in shade processed and screened through a $2 \mathrm{~mm}$ sieve. After sieving all the samples were packed in polythene bags for analysis

\section{DISCUSSION}

3.1 Bulk density The bulk density is positively related to particle density (0.986), hydraulic conductivity (0.989), $\mathrm{pH}(0.950)$ and negatively related to thermal conductivity(0.972), Porosity (0.992), water holding capacity (0.992), volume expansion(0.882), organic carbon(0.986), EC(0.990), $\mathrm{N}$ (0.983), P (0.991), K(0.935). In the case of bulk density, the fitted best equation along with the RSquare value and the significant of the coefficients is

$\mathrm{y}=1.9987-0.0045 \mathrm{x} ; \mathrm{R}^{2}=0.9821 * *$ Where $\mathrm{y}$ is the bulk density and $\mathrm{x}$ is the level of amendment. Here, $\mathrm{R}$ - Square is almost near to one for the cubic equation .This shows that 99.7 percent of the variations in the bulk density in the soil is being explained by the levels of amendments made .Here the coefficient of $x$ is negative indicating the decreasing value of the bulk density with respect to increase in the values in the amendments. That is addition of Goat manure brings down the bulk density. That is a unit increase in the value of the amendment level would produce a decrease of 0.0045 units in the bulk density 


\subsection{Particle density}

The correlation table reveals that the particle density is positively related to bulk density (0.986), hydraulic conductivity (0.979), $\mathrm{pH}(0.963)$ and negatively associated with thermal conductivity (0.994), N (0.958), P (0.988), K(0.968), volume expansion (0.929),porosity (0.983), EC (0.975) water holding capacity $(0.982) \mathrm{pH}(0.963)$ and organic carbon (0.969). The fitted equation is

$$
\mathrm{y}=3.3586-0.0118 \mathrm{x} ; \mathrm{R}^{2}=0.9849^{* *}
$$

Increase in the amendment rate brings only decrease in the particle density. That is addition of Goat manure brings a reduction in the particle density. The initial particle density of the original soil is nearly 3 units. The high significant R- Square value expresses the fact that about 99 percent of the variations in the behavior of particle density is being explained by the different amendment levels in Goat manure used in the experiment.

\subsection{Porosity}

The porosity of the soil has got positive association with volume expansion(0.906), water holding capacity (0.990), thermal conductivity (0.976), EC (0.969), organic carbon (0.969), N (0.973), $\mathrm{P}(0.982)$, $\mathrm{K}(0.948)$ and negative association with bulk density (0.992), pH (0.942), , hydraulic conductivity $(0.981)$, particle density $(0.983)$. The best equation fitted in this case is

$$
\mathrm{y}=41.071+0.0754 \mathrm{x} ; \mathrm{R}^{2}=0.9765 * *
$$

The sign of the $\mathrm{x}$ term ascertain the fact expressed through simple correlations. That is increase in the amendment levels will increase the porosity level of the soil. The initial porosity of the soil seems to be high and equal to 41 units. This high value might be the cause for high depletion of water in theri soils. Moreover, the high value of R- Square ascertains that 99 percent of the variations in porosity is being explained by the amendments through Goat manure. Further, a unit increase in the amendment level increase the porosity by 0.0754 units.

\subsection{Water holding capacity}

The correlation table reveals that the water holding capacity has positive association with porosity (0.990), volume expansion (0.908) thermal conductivity (0.970), EC (0.978), organic carbon
(0.974),N (0.968), P (0.991),K(0.948) and negative association with bulk density (0.992), hydraulic conductivity (0.982), $\mathrm{pH}(0.955)$, particle density (0.982), and $\mathrm{pH}(0.955)$. The best equation fitted is

$$
y=20.204+0.1815 x ; R^{2}=0.9869^{* *}
$$

The positive value of the coefficient of $x$ agrees with the correlation results .The R-Square is equal to 0.987 , which is significant at 0.01 level of probability indicating that the 98.7 percent of variations in the water holding capacity is being explained by the amendment levels. Also the initial level of water holding capacity of the soil is around 20 units. Again a unit increase in the amendment could increase the water holding capacity of the soil by 0.1815 units. The equation to estimate the needed amendment level for the desired water holding capacity level is given by

0.1815

\subsection{Volume expansion}

Volume expansion has positive relation with porosity $(0.906)$, water holding capacity (0.908), thermal conductivity (0.950), EC (0.853) ,organic carbon (0.831), N (0.822), $\mathrm{P}(0.905), \mathrm{K}(0.980)$, and negative relation with bulk density (0.882), hydraulic conductivity (0.871), particle density (0.929), and $\mathrm{pH}(0.944)$. The best regression equation fitted through least square in this case is

$y=2.7813+0.0562 x ; R^{2}=0.8604 * *$ The coefficient of $\mathrm{x}$ in the equation is positive which is in agreement with the correlation results. That is increase in amendment increases the volume expansion of the soil. The R-Square is very high indicating the fact that 98 percent of the variations in the volume expansion is being determined by the amendments included in the experiment. The regression constant is nearly 2.78 which indicates the initial volume expansion of the Theri-soil. Moreover, a unit increase in the amendment increases the volume expansion by 0.0562 units.

\subsection{Hydraulic conductivity}

The correlation table reveals that the hydraulic conductivity is positively related to bulk density (0.989), $\mathrm{pH}(0.940)$ and particle density (0.979) and negatively associated with thermal conductivity (0.962), porosity (0.981), EC (0.992), N (0.993), P $(0.993), \mathrm{K}(0.910)$, volume expansion $(0.871)$, water 
holding capacity (0.982), and organic carbon.(0.995). The best fitted equation is

$$
\mathrm{y}=235.24-0.8434 \mathrm{x} ; \mathrm{R}^{2}=0.9781 * *
$$

The relationship expressed in the simple correlation coefficient is being reflected by the negative values of the $\mathrm{x}$ term. The initial hydraulic conductivity level of the soil is nearly 235.24.The $\mathrm{R}-$ Square is 0.99 expressing the fact that 99 percent of the variations in the hydraulic conductivity of the soil is being decided by the amendment levels considered in the experiment .The coefficient of $\mathrm{x}$ is low which expresses the slow responsiveness due to the changes in the amendment levels. Again a unit increase in the amendment level will decrease the hydraulic conductivity by 0.8434 units.

\subsection{Thermal conductivity}

The correlation table reveals that the thermal conductivity is positively associated with porosity (0.976),water holding capacity (0.970), EC (0.957), $\mathrm{N}(0.936), \mathrm{P}(0.979), \mathrm{K}(0.982)$ organic carbon (0.948), volume expansion (0.950) and is negatively associated with $\mathrm{pH}(0.966)$, particle density $(0.994)$, hydraulic conductivity (0.962), and bulk density $(0.972)$. The thermal conductivity corresponding to each level of amendment was taken as the dependent variable (y) and the different levels of amendments (x) were taken as the independent variable. The best form of equation in the mathematical form along with their R-Square value and the level of significance is

$\mathrm{y}=0.1245+0.0003 \mathrm{x} ; \mathrm{R}^{2}=0.9701 * *$ Here the $\mathrm{R}-$ Square value is greater than 0.97 which is significant at 0.01 level of probability indicating the fact that more than 97 percent of the variations in the thermal conductivity level is being explained by the levels of Goat manure added to the soil. Irrespective of the type of function fitted, the regression constant value is around 0.1245 that is the initial thermal conductivity of the soil without the addition of the Goat manure. Moreover as per the value of the coefficient of $\mathrm{x}$ in the linear trend equation a unit increase in the amendment level will bring an increase of 0.0003 units in the levels of the thermal conductivity.

\section{$3.8 \mathrm{pH}$}

It is observed from the correlation table that $\mathrm{pH}$ has positive association with bulk density (0.950), particle density (0.963), hydraulic conductivity (0.940), and negative association with organic carbon (0.923), volume expansion (0.944), $\mathrm{N}$ (0.903), $\mathrm{P}(0.968)$, $\mathrm{K}(0.963)$, water holding capacity (0.955), EC (0.947), volume expansion(0.944) and porosity (0.942). Thus it's behaviour also should be parallel to that of bulk density, particle density, hydraulic conductivity. The best equation selected is

$y=7.2667-0.0009 x ; R^{2}=0.941 *$ The sign of $x$ in the equation confirm the behaviour with the results obtained through simple correlation analysis that amendment decreases the $\mathrm{pH}$ level .The R-Square value indicates that about 96.3 percent of the variations in $\mathrm{pH}$ is being determined by the amendment levels used in the equation. The $\mathrm{pH}$ without any amendment is nearly 7.2667 units.

\subsection{Electrical conductivity (EC)}

The correlation coefficients of EC is positively associated with porosity (0.969) water holding capacity $(0.978)$, volume expansion $(0.853)$, thermal conductivity(0.957), organic carbon(0.994), $\mathrm{N}(0.984)$, $\mathrm{P}(0.992)$ and $\mathrm{K}(0.904)$ negatively associated with bulk density $(0.990)$, particle density $(0.975)$, hydraulic conductivity $(0.992)$ and $\mathrm{pH}(0.947)$. The best equation in the case of EC is

$\mathrm{y}=1.05+0.0013 \mathrm{x} ; \mathrm{R}^{2}=0.9684 * *$ Where $\mathrm{y}$ is the $\mathrm{EC}$ and $\mathrm{x}$ is the levels of amendments. Here R-square is 0.9884 which is significant at one percent level of probability indicating the fact that 98.84 percent of the variations in the EC level is being explained by the different levels of goat manure added to the soil . The regression constant gives the EC level of original theri soil. The coefficient of $\mathrm{x}$ in the linear equation indicate that a unit increase in the level of amendment will increase the EC level of the soil by 0.0013 units. That is amendments help in increasing the level of EC in the original soil. This is again confirmed by the negative association of bulk density (0.990) with this and the positive association of 0.978 with water holding capacity.

\subsection{Organic carbon}

The organic carbon has positive correlation of 0.969 , $0.974,0.831,0.948,0.994,0.991,0.987$ and 0.888 respectively with porosity, water holding capacity, volume expansion, thermal conductivity, EC, N, P,K and negative association of $0.986,0.969,0.995$ and 0.923 and with bulk density, particle density ,hydraulic conductivity and $\mathrm{pH}$. The best least square equation fitted is 
$\mathrm{y}=0.1913+0.0024 x ; \mathrm{R}^{2}=0.9535^{* *}$

The R-Square is 0.987 which is significant at the highest level of probability indicating the fact that the amendments chosen could explain 98.7 percent of the variations in the organic carbon .The positive coefficient for $\mathrm{x}$ gives the confirmation of the fact derived from simple correlations. That is increase in the levels of amendments bring additional organic carbons.

\subsection{Nitrogen}

The nitrogen level is positively associated with porosity (0.973) water holding capacity (0.968), volume expansion (0.882), thermal conductivity (0.936), EC (0.984), organic carbon (0.991), P(0.975) and $\mathrm{K}$ (0.870)and negatively associated with bulk density (0.983), particle density (0.958), $\mathrm{pH}(0.903)$ and hydraulic conductivity(0.993). In the case of nitrogen the regression equation selected is

$\mathrm{y}=77.067+0.417 \mathrm{x} ; \mathrm{R}^{2}=0.9424$. The $\mathrm{R}$ - Square is 0.996 which is significant at the highest level indicating the amount of fitness i.e. to say that changes in the levels of amendments could decide the changes in nitrogen at 99.6 percent level. The initial nitrogen level is around 77.067 units and the response in changes is higher than that for EC. Moreover additional levels of amendments could increase the nitrogen level and a unit increase in the amendment could increase the level of nitrogen by 0.417 units. The positive association of 0.968 with water holding capacity negative association of 0.983 with bulk density, and the negative association of 0.993 with the hydraulic conductivity again justify this.

\subsection{Phosphorus}

The phosphorus level is positively associated with porosity (0.982) water holding capacity (0.991), volume expansion (0.905), thermal conductivity (0.979), EC (0.992), organic carbon (0.987), N(0.975) and $\mathrm{K}$ (0.943)and negatively associated with bulk density(0.991),particle density(0.988), $\mathrm{pH}(0.968)$ and hydraulic conductivity(0.993). The best equation fitted is

$$
\mathrm{y}=19.013+0.5165 \mathrm{x} ; \mathrm{R}^{2}=0.9935^{* *} \text { The positive }
$$
value of the coefficient of $x$ agrees with the correlation results .The R-Square is equal to 0.995 , which is significant at 0.01 level of probability indicating that the 99.5 percent of variations in the phosphorus is being explained by the amendment levels. Also the initial level of phosphorus of the soil is around 19 units. Again a unit increase in the amendment could increase the phosphorus of the soil by 0.5165 units.

\subsection{Potassium}

Potassium level of the soil is directly related porosity (0.948), water holding capacity (0.948), volume expansion (0.980), thermal conductivity (0.982), EC (0.904), organic carbon (0.888), $\mathrm{N}(0.870)$ and $\mathrm{P}$ (0.943)and negatively related with bulk density(0.935), particle density(0.968), $\mathrm{pH}(0.963)$ and hydraulic conductivity $(0.910)$. The best equation in this case is

$y=415.13+0.5448 x ; R^{2}=0.9156^{* *}$

The coefficient of $\mathrm{x}$ in the equation ispositive and this is a confirmation to the results on simple correlation. The initial value of the soil Potassium nearly 415.13 units and a unit increase in the value of the amendment will induce an increase of 0.5448 units in the Potassium. The R- Square 0.9942 indicating that 99.4 percent of the variations in the Potassium is explained by the different levels of amendments.

\section{Results and Conclusion}

Addition of the Goat Manure amendment with Theri Soil decreases the bulk density, particle density, $\mathrm{pH}$ and hydraulic conductivity but increases water holding capacity, Volume Expansion, Porosity, Thermal conductivity, EC,N,P,K and organic carbon. It is generally agreed that the bulk density of $1.5-1.6$ $\mathrm{g} / \mathrm{cm}^{3}$ is critical for root growth of most of the plants. (Ayres et al. 1973). In this study the convenient root growth condition for the plants is achieved for $\mathrm{T}+90 \%, \mathrm{~T}+100 \%$ and $\mathrm{T}+80 \%$ amendments. The total porosity varies in the neighborhood of $50 \%$ (Baver, 1959) Here in the above treatments range from $34 \%$ to $43 \%$. The $\mathrm{pH}$ value beyond 9 is undesirable on account of alkali hazards Neither is the $\mathrm{pH}$ value below 4.5 good as availability of nutrients of plants becomes a limiting factor. The values of $\mathrm{pH}$ for all the amendments are favorable for cultivation purpose. Crop yields generally do not significantly decrease until the salt concentration in the soil solution exceeds the threshold level which can differ for different crops and their varieties. The major soil physical constraints identified are low water retention and high permeability. The desired increase of water holding capacity will improve the ability to supply the nutrients to soil. The hydraulic conductivity is 
International Journal of Trend in Scientific Research and Development (IJTSRD) ISSN: 2456-6470

considerably controlled from very rapid stage to moderately rapid stage. This is because the pplications of organic manures and pond sediments decrease the bigger pores and increase the smaller pores (Anonymous, 2002). Here in all the treatments water holding capacity increased and attained the maximum value of $80 \%$ cent and the hydraulic conductivity reduced to the minimum value of $145 \mathrm{~mm} / \mathrm{hr}$. $\mathrm{T}+$ $90 \%, \mathrm{~T}+80 \%$ and $\mathrm{T}+100 \%$ combinations were better than the other combinations for the purpose of cultivation. Increase of organic Carbon improves the growth condition of the crops. Here NPK values also increased to more than $50 \%$. Giving more importance to the major soil physical constraint namely the water retention and the permeability $\mathrm{T}+90 \%$ amendment treatment could be predicted as the best among all the treatments.

Table 1: Change of Physical and chemical properties of Theri soil amended with Goat Manure

\begin{tabular}{|l|l|l|l|l|l|l|l|l|l|l|l|l|l|}
\hline$\%$ & B.D & P.D & Porosity & W.H.C & V.E & H.C & T.C & pH & EC & OC & N & P & K \\
\hline 10 & 1.95 & 3.333 & 41.6956 & 22.574 & 2.44 & 223 & 0.125 & 7.26 & 1.07 & 0.23 & 84 & 25.7 & 412 \\
\hline 20 & 1.9 & 3.077 & 42.522 & 23.53 & 3.62 & 215 & 0.131 & 7.25 & 1.08 & 0.25 & 88 & 29.8 & 425 \\
\hline 30 & 1.86 & 2.963 & 43.37 & 24.846 & 4.444 & 210 & 0.135 & 7.24 & 1.09 & 0.264 & 90 & 33.4 & 431 \\
\hline 40 & 1.82 & 2.857 & 44.65 & 28.136 & 5.503 & 203 & 0.139 & 7.24 & 1.09 & 0.28 & 93 & 38.6 & 442 \\
\hline 50 & 1.77 & 2.759 & 45 & 29.271 & 6.267 & 200 & 0.143 & 7.2 & 1.11 & 0.29 & 94 & 44.5 & 450 \\
\hline 60 & 1.74 & 2.667 & 45.543 & 31.306 & 6.797 & 187 & 0.143 & 7.2 & 1.12 & 0.32 & 99 & 49.4 & 452 \\
\hline 70 & 1.7 & 2.51 & 45.696 & 33.09 & $7 e s e$ & 180 & 0.147 & 7.2 & 1.14 & 0.35 & 102 & 55.6 & 456 \\
\hline 80 & 1.67 & 2.424 & 46.696 & 33.431 & 7.7 & 166 & 0.152 & 7.19 & 1.15 & 0.38 & 110 & 61.2 & 458 \\
\hline 90 & 1.6 & 2.352 & 48 & 36.74 & 7.968 & 160 & 0.152 & 7.19 & 1.16 & 0.39 & 116 & 63.4 & 461 \\
\hline 100 & 1.51 & 2.162 & 49 & 38.92 & 8 & 145 & 0.156 & 7.18 & 1.19 & 0.46 & 124 & 72.6 & 464 \\
\hline
\end{tabular}

\section{Abbreviations:}

B.D - Bulk Density P.D - Particle Density

W.H.C - Water Holding Capacity

V.E - Volume Expansion

H.C - Hydraulic Conductivity

T.C - Thermal Conductivity

$\mathrm{N}$ - Nitrogen P - Phosphorus K - Potassium

EC-Electrical Conductivity OC- Organic Carbon

\section{REFERENCES}

1. Jawahar D, Studies on the sand dunes (theri) in the coastal belt of V. O.Chidambaranar and Nellai Kattabomman districts, Tamilnadu Agricultural University Ph.D. Thesis, Coimbatore, Tamilnadu;1996.

2. Subramanian V. Land use planning for management of agricultural resources, final report, TNAU, Killikulam, T.N. SouthIndia. 2004;45-46.

3. Mayalagu K, Sree Ramulu US. N, P and K (Total and available) status of major series of red soils of Coimbatore district, TamilNadu. Madras Agric. J. 1983;70:51-54. 
4. Gorbunov NI. Effects of method of soil properties. Agrochimiya.1980;50:93-100.

5. Keen BA, Raczkowski H. Relation between the clay content and certain physical properties of soil. Journal of Agricultural Science. $1921 ; 11: 441-449$.

6. Jackson MC. Soil chemical analysis.Prentice Hall Pvt,Ltd.NewDelhi;1973.

7. Walkley A, Black JA. An examination of the Degt Jareft method for determination of soil organic matter and proposed modification of chromic acid titration method. Sci. Soil. 1934;37:29-38.

8. Subbaiah BV, Asija GC. A rapid procedure for the determination of available nitrogenin soils. Current Science. 1956;25:259-262.

9. Hussain N, Hassan G, Arshadullah M, Mujeeb F. Evaluation of amendments for the improvement of physical properties of sodic soil. Int. J. Agric. and Biology. 2001;3(3):319-322. 